\title{
Death in infancy from unrecognised congenital heart disease
}

\author{
Majd Abu-Harb, Edmund Hey, Christopher Wren
}

\begin{abstract}
This study was undertaken to identify all congenital heart disease in infancy, including deaths before diagnosis, to provide a truer picture of the spectrum of congenital heart disease and to assess the 'treatability' of those dying before diagnosis. All births, infant deaths, and surviving babies with congenital heart disease in one health region in 1985-90 were identified and were classified as 'complex', 'significant', or 'minor'.

Of the 1074 infants diagnosed in infancy, 185 died and 56 of these $(30 \%)$ died undiagnosed. Severe non-cardiac malformations were present in 29 of the 56 while 27 were otherwise normal. Cardiovascular abnormalities in the latter group were complex in 13/27 and significant in 14/27.

Identification of undiagnosed cardiovascular anomalies will improve epidemiological evaluation of congenital heart disease and, more importantly, earlier recognition of treatable abnormalities may reduce mortality.

(Arch Dis Child 1994; 71: 3-7)
\end{abstract}

This study was performed to identify all babies dying from unrecognised congenital heart disease, and to determine whether any of the deaths might have been avoided if the diagnosis had been made in life. In order to achieve such aims it is necessary to have: a well defined catchment population with accurate and reliable registration of all births and deaths; clearly identified referral routes of all patients with congenital heart disease, preferably to a single tertiary referral centre; and a central registry of all infant deaths including necropsy data on all deaths without a confirmed antemortem diagnosis. ${ }^{12}$ These criteria are met in the Northern region of England, and allow confidence in the findings of this study.

Few previous studies of the prevalence of congenital heart disease have been able to include cases causing death before diagnosis. Where data were available, with one exception $^{1}$ they have not been analysed separately. ${ }^{3-6}$ Death before diagnosis is of interest to paediatric cardiologists for three main reasons. Firstly, some babies may have treatable abnormalities so better education of the primary health care team may detect them in life. Secondly, by excluding these patients, who are likely to have more severe disease, a false impression will be gained of the prevalence and spectrum of congenital heart disease. Thirdly, as the number of cases of heart disease recognised after birth is often used in validating antenatal screening for cardiac malformations, incomplete ascertainment of undiagnosed abnormalities will lead to overestimation of the success of antenatal diagnosis.

\section{Methods}

The Northern region comprises the counties of Cumbria, Northumberland, Tyne and Wear, Durham, and Cleveland and has a population of 3076600 , with close to 40000 live births per year. All cases of suspected congenital heart disease from 15 of 16 health districts are referred to the single regional paediatric cardiology centre at Freeman Hospital. For geographical reasons patients from South Cumbria (population 172 500) are referred elsewhere; because of this all births and deaths and patients with congenital heart disease from that district have been excluded from this study. With that exception, there is no outward cross border referral of infants with congenital heart disease.

The Northern regional survey of perinatal, late neonatal, and infant mortality (NRS) was set up in 1981 to collect data on all perinatal and late neonatal deaths and data collection was expanded to include all infant deaths from $1988 .^{7}$ A check with the Office of Population Census and Surveys showed no deaths in 1985-7 in the age group 1-12 months which would have been missed before the survey included all infant deaths. Since 1985 the Northern regional fetal abnormality survey (NRFAS) has collected data on all serious congenital malformations in fetuses, stillborn and liveborn infants. Its methodology has been reported previously and is well validated. ${ }^{8}$

All cases of congenital heart disease presenting in infancy and known to the regional paediatric cardiology centre and the NRFAS in 1985-90 were identified. They were analysed by diagnosis and by age at presentation.

All cases of death from, or with, congenital heart disease in the NRS were identified by examination of all necropsy reports in the survey for the years 1985-90. By comparison 
with deaths already known to the regional paediatric cardiology centre, we identified all deaths with necropsy diagnosis of congenital heart disease, where there had been no confirmation of cardiac disease in life. We examined records of all such babies dying with unrecognised congenital heart disease to establish the age at death, the postmortem diagnosis, the place of death, the presence of other congenital abnormalities, and the history before death.

The diagnosis in every case was confirmed by echocardiography, cardiac catheterisation, surgery, or necropsy. Clinical suspicion alone of congenital heart disease was not accepted. We also excluded cases in which congenital heart disease was suspected by a district paediatrician but not referred for confirmation before the age of 12 months. Obviously this will lead to slightly lower ascertainment, mostly of 'minor' abnormalities - mainly small ventricular septal defects and mild aortic or pulmonary valve stenosis - although some 'significant' malformations are also referred after infancy.

This study is retrospective and therefore any missing data or pathological diagnoses cannot be checked. The diagnosis in unsuspected congenital heart disease relies entirely on the necropsy diagnosis by the pathologist and no specimens were available for retrospective analysis.

We excluded from the study 18 cases in which termination of pregnancy was performed in 1985-90 because of, or in the presence of, congenital heart disease, and all stillbirths. Many cases in which antenatal diagnosis of severe congenital heart disease is made will result in death in utero and it is obviously not possible to decide whether an individual case would have resulted in live birth or antenatal death.

In order to assess the 'treatability' of congenital heart disease, each cardiac abnormality was designated 'complex', 'significant', or 'minor'. Complex congenital heart disease was that where a valve or chamber was atretic or hypoplastic (for example hypoplastic left heart syndrome or pulmonary atresia). Malformations described as significant were those in which four chambers and four valves were present and treatment was necessary (for example coarctation of the aorta or transposition of the great arteries). Minor malformations were those with normal cardiac connections where no intervention was necessary - mainly small ventricular septal defects and less severe aortic valve stenosis or pulmonary valve stenosis. Exceptions to this simple classification were endocardial fibroelastosis, which was assigned to complex

Table 1 Summary of classification of congenital heart disease and type of presentation

\begin{tabular}{lllll}
\hline & Recognised & $\begin{array}{l}\text { Recognised } \\
\text { CHD alive at }\end{array}$ & $\begin{array}{l}\text { Death with } \\
\text { unrecognised } \\
\text { CHD and } \\
\text { other major } \\
\text { malformation }\end{array}$ & $\begin{array}{l}\text { Death with } \\
\text { unrecognised } \\
\text { CHD and } \\
\text { no other } \\
\text { abnormality }\end{array}$ \\
Classification & 61 & 80 & 7 & 13 \\
\hline Complex & 514 & 49 & 22 & 14 \\
Significant & 314 & 0 & 0 & 0 \\
Minor & & 0 & 0 & 0 \\
\hline
\end{tabular}

$\mathrm{CHD}=$ congenital heart disease. congenital heart disease, and complete atrioventricular septal defect, which was assigned to significant congenital heart disease. Our complex and significant classifications correlate fairly well with whether or not a biventricular repair of the heart is feasible, that is, one which results in utilisation of four chambers and four valves. We excluded babies undergoing ligation of patent ductus arteriosus associated with prematurity and those with supraventricular tachycardia or complete atrioventricular block but no structural cardiovascular abnormality.

\section{Results}

During the six year period 1985-90, in the 15 health districts (population 2904 100), there were 230654 live births, a birth rate of 13.2 per 1000 population. There were 1979 early neonatal, late neonatal, and infant deaths - an infant mortality rate of 8.6 per 1000 live births.

During the same period 1074 patients were diagnosed in infancy as having congenital heart disease (see table 1). Of these, 1018 (95\%) presented in life to the regional paediatric cardiology centre and $56(5 \%)$ were identified from the NRS.

Data for this study were collected retrospectively in part and at the outset there was no comprehensive central register of congenital heart disease in the region. Identification from hospital computer records of all patients seen as day cases or requiring admission to hospital (therefore including all complex and significant congenital heart disease) was straightforward but retrospective identification of minor congenital heart disease in the early years, especially 1985 and 1986, was more difficult. Analysis by year of presentation showed a stable number of complex and significant congenital heart disease and increasing numbers of minor congenital heart disease as ascertainment improved. The overall prevalence at live birth of 4.7 per 1000 compares well with the very few recent reports which have included only congenital heart disease presenting in the first year of life and proved by echocardiography, cardiac catheterisation, surgery, or necropsy. ${ }^{4-11}$

There were 185 deaths in infancy from congenital heart disease, accounting for $43 \%$ of all infant deaths due to congenital malformation and $9 \%$ of total infant mortality. One hundred and twenty nine of 185 deaths $(70 \%)$ occurred in babies with previously diagnosed congenital heart disease, while in 56 deaths (30\%) congenital heart disease was unsuspected or unconfirmed (see table 1). (These 56 account for $2.8 \%$ of all infant deaths.) Seventy per cent of the first year deaths with congenital heart disease occurred within the first four weeks of life and $85 \%$ within the first four months.

The 56 deaths from unrecognised congenital heart disease comprised 29 babies with other severe abnormalities (mainly trisomy 13, 18 , and 21 ) and 27 babies who were otherwise normal. Of the latter group, $13(48 \%)$ had complex congenital heart disease, $14(52 \%)$ had significant congenital heart disease, and 
Table 2 Diagnoses and leading causes of death among all congenital heart defects

\begin{tabular}{lccc}
\hline Presenting diagnosis & Total cases & $\begin{array}{l}\text { Total (\%) } \\
\text { deaths }\end{array}$ & $\begin{array}{l}\text { Death (\%) } \\
\text { without diagnosis }\end{array}$ \\
\hline Endocardial fibroelastosis & 4 & $4(100)$ & $4(100)$ \\
Hypoplastic left heart & 26 & $26(100)$ & $4(15)$ \\
Truncus arteriosus & 29 & $22(76)$ & $6(21)$ \\
Interruption of aortic arch & 15 & $10(67)$ & $3(20)$ \\
Tricuspid atresia & 15 & $5(33)$ & $2(13)$ \\
Pulmonary atresia & 44 & $14(32)$ & $1(2)$ \\
Complete atrioventricular septal defect & 80 & $24(30)$ & $12(15)$ \\
Aortic valve stenosis & 52 & $11(21)$ & $3(6)$ \\
Transposition of great arteries & 79 & $14(18)$ & $4(5)$ \\
Coarctation of aorta & 52 & $6(12)$ & $2(4)$ \\
Tetralogy of Fallot & 60 & $5(8)$ & $2(3)$ \\
Ventricular septal defect & 353 & $15(4)$ & $8(2)$ \\
Other & 265 & $29(11)$ & $5(2)$ \\
Total & 1074 & $185(17)$ & $56(5)$ \\
\hline
\end{tabular}

Table 3 Death from unsuspected heart disease in babies with no other abnormality

\begin{tabular}{lll}
\hline Diagnosis & $\begin{array}{l}\text { No of } \\
\text { cases }\end{array}$ & Age at death \\
\hline $\begin{array}{l}\text { Complex heart disease } \\
\text { Endocardial fibroelastosis }\end{array}$ & 4 & $1,1,1,17$ days \\
$\begin{array}{l}\text { Hypoplastic left heart } \\
\text { Truncus arteriosus }\end{array}$ & 3 & $2,2,5$ days \\
$\begin{array}{l}\text { Tricuspid atresia } \\
\text { Pulmonary atresia }\end{array}$ & 2 & 1,30 days \\
Other complex lesions & 1 & 1 day \\
$\begin{array}{l}\text { Significant heart disease } \\
\text { Interruption of aortic arch }\end{array}$ & 2 & 1,10 days \\
Complete atrioventricular septal & 3 & $3,7,8$ days \\
$\quad$ defect & 2 & 17,28 days \\
Aortic valve stenosis & 2 & 2,2 months \\
Transposition of great arteries & 2 & 2,4 hours \\
Coarctation of the aorta & 2 & 9,18 days \\
Tetralogy of Fallot & 1 & 1 day \\
Pulmonary stenosis & 1 & 11 hour \\
Mitral regurgitation & 1 & 11 days \\
\hline
\end{tabular}

there were no deaths with minor heart disease (see table 1).

Table 2 shows the commonest types of congenital heart disease in babies dying in infancy. The abnormalities with the highest mortality were hypoplastic left heart syndrome, truncus arteriosus, and interruption of the aortic arch, while those most likely to present with death before diagnosis were endocardial fibroelastosis, truncus arteriosus, interruption of the aortic arch, hypoplastic left heart syndrome, and complete atrioventricular septal defect.

Table 3 gives details of the 27 deaths in which there was no other congenital abnormality. Of those with significant congenital heart

Table 4 Deaths in babies with severe non-cardiac abnormalities and unrecognised heart disease

\begin{tabular}{lcl}
\hline Non-cardiac diagnosis & No & Cardiac diagnosis \\
\hline $\begin{array}{l}\text { Trisomy 21 } \\
\text { Trisomy 18 }\end{array}$ & 6 & $\begin{array}{l}\text { Complete AV septal defect (6) } \\
\text { Complete AV septal defect (2) }\end{array}$ \\
& 9 & $\begin{array}{l}\text { Ventricular septal defect (3) } \\
\text { Hypoplastic left heart (1) }\end{array}$ \\
Tricuspid atresia (1) \\
Trisomy 13 & & $\begin{array}{l}\text { Tetralogy of Fallot (1) } \\
\text { Transposition of great arteries (1) }\end{array}$ \\
$\begin{array}{l}\text { Unbalanced translocation } \\
\text { Neural tube defects }\end{array}$ & 5 & $\begin{array}{l}\text { Complete AV septal defect (1) } \\
\text { Ventricular septal defect (3) } \\
\text { Truncus arteriosus (1) }\end{array}$ \\
$\begin{array}{l}\text { Renal agenesis } \\
\text { Ventricular septal defect (1) }\end{array}$ \\
$\begin{array}{l}\text { Tracheal atresia } \\
\text { Holt-Oram syndrome, oesophageal and anal } \\
\text { atresia }\end{array}$ & 1 & $\begin{array}{l}\text { Truncus arteptal defect (1) } \\
\text { Truncus arteriosus (1) }\end{array}$ \\
$\begin{array}{l}\text { Smith-Lemli-Opitz syndrome } \\
\text { Arthrogryposis and tentorial tear } \\
\text { Total }\end{array}$ & 2 & $\begin{array}{l}\text { Total anomalous pulmonary venous } \\
\text { connection (1) }\end{array}$ \\
\hline
\end{tabular}

$\mathrm{AV}=$ atrioventricular. disease, the four deaths from cyanotic heart disease all occurred within 30 hours of birth (three before discharge from hospital), while the seven deaths from obstructive left heart lesions occurred after discharge at age 3-62 days. Four of five babies, with either coarctation of the aorta or interruption of the aortic arch, died after readmission to their local hospital aged 3-18 days. No details of time from readmission to death are available to help assess whether these deaths might have been preventable. Two babies with severe aortic stenosis (both aged 2 months) and one with interruption of the aortic arch (aged 6 days) died suddenly at home. There were three deaths from significant heart disease that did not fit into either of these categories; two babies with complete atrioventricular septal defects, one of whom died in hospital and the other on arrival in the accident and emergency department, and one with severe mitral regurgitation who died in hospital.

The group of 29 with serious non-cardiac congenital malformations had a range of cardiac defects, $23(79 \%)$ of which were significant rather than complex. Ventricular septal defect $(28 \%)$ and complete atrioventricular septal defect $(34 \%)$ were the most common abnormalities. Table 4 gives details of the non-cardiac and cardiac abnormalities in this group. In such cases it is difficult in retrospect to be completely sure of the cause of death, even though it had usually been ascribed to 'heart failure'. There were two other deaths in babies with multiple congenital abnormalities in which death had been certified as due to heart failure. However, no necropsy was performed in either of these cases and, as it was not possible to substantiate the clinical suspicion of congenital heart disease, they have not been included in this series.

\section{Discussion}

This study has shown that the diagnosis was unrecognised in life in $30 \%$ of all babies dying in infancy from congenital heart disease. About half were otherwise normal, and half of these had a cardiac abnormality categorised as significant (as opposed to complex), which was potentially suitable for eventual repair. Assuming these findings are generally representative, they suggest that about 200 infants die each year in the UK with unrecognised congenital heart disease and 100 or so die from isolated unsuspected cardiac abnormalities. In countries with less ready access to health care the proportion may well be higher. ${ }^{12}$

Although there have been many previous studies of the prevalence of congenital heart disease, it is difficult to compare them as many features are not standardised. Reports from the pre-echocardiography era ${ }^{13-15}$ often relied on clinically suspected diagnoses and generally state a higher prevalence than more recent reports that relied on confirmed diagnoses.41011 Not all congenital heart disease presents in infancy and those studies with longer follow up obviously detect more cases. ${ }^{314-16}$ We have included only patients 
with diagnoses confirmed by echocardiography, cardiac catheterisation, surgery, or necropsy and presenting before the first birthday in order to be able to compare our results with those of the New England regional cardiac program ${ }^{13}$ and the Baltimore-Washington infant study. ${ }^{11}$

In the one previous study which examined death from unrecognised congenital heart disease, Rubin et al found 32 cases at necropsy in a total of 1527 infants $(2 \cdot 1 \%){ }^{1}$ This compares with our finding that $5 \%$ of all cases were unrecognised before death. Rubin et al found $72 \%$ to have 'severe' cardiac malformations but their classification of severe included transposition of the great arteries, tetralogy of Fallot, and complete atrioventricular septal defect, all of which were in our significant group. They also found a higher proportion to have major non-cardiac malformations $(66 \%$ compared with our $48 \%$ ) and only $6 \%$ of deaths from unrecognised heart disease were in otherwise normal babies with 'less severe' heart disease (compared with our finding of $25 \%$ of deaths in babies with no other abnormality and significant heart disease: see table 1). The other main difference between the two reports is that Rubin et al found 18 of $32(56 \%)$ deaths occurred within one day of birth whereas we found that the majority survived more than one day (table 3).

The identified prevalence of heart disease causing death in infancy will be greatly influenced by the necropsy rate and the sensitivity of necropsies in detecting cardiovascular malformations. The necropsy rate in the final year of the Baltimore-Washington report ${ }^{1}$ was $52 \%$ whereas in our study it was $73 \%$ of all live births and $84 \%$ of all deaths not due to an existing identified cardiac malformation or not occurring while undergoing intensive neonatal care in a tertiary referral centre (when it is unlikely that a major cardiac abnormality would have been missed). Even so, our study probably underestimates the prevalence of congenital heart disease as not all babies had necropsies and some abnormalities (such as coarctation of the aorta, or total anomalous pulmonary venous connection) could be missed at necropsy. In such cases, in the absence of any identified abnormality, death would probably be ascribed to 'sudden infant death syndrome'.

Babies with no non-cardiac abnormality who died from significant congenital heart disease fall mainly into two groups (see table 3). Those with cyanotic congenital heart disease all died early and most died in hospital. If such babies are to be recognised in future, hospital paediatricians need to be more aware of the possibility of early neonatal death from cyanotic heart disease and more ready to institute treatment with prostaglandin and ventilatory support before a final diagnosis is made.

Those with obstructive left heart lesions all died after discharge from hospital, either at home or shortly after readmission with heart failure. If such babies are to be identified, the responsibility lies with the primary health care team. It should be more widely recognised that a normal neonatal examination in the first two or three days of life does not exclude serious heart disease and abnormalities such as coarctation of the aorta and interruption of the aortic arch usually present in the first two weeks of life but not in the first two days. Screening for congenital heart disease is carried out in this country at 6-8 weeks of age, but a check at this age is too late for many babies with coarctation of the aorta and most with interruption of the aortic arch who present before this time. In our series two babies with aortic stenosis died with apparent sudden infant death syndrome at the age of 2 months and both had been examined at the age of 6 weeks when a murmur should have been audible.

In babies with isolated congenital heart disease it is clear that the abnormality (such as coarctation of the aorta or transposition of the great vessels) was the cause of death. In those with both a severe non-cardiac abnormality (such as a chromosomal anomaly) and a cardiac malformation (such as a ventricular septal defect or complete atrioventricular septal defect) it is difficult to be completely sure, in retrospect, about the cause of death. ${ }^{11718}$ Similarly, babies with multiple abnormalities may not have been investigated further, so that while heart disease may be unrecognised it is not necessarily unsuspected. Not all babies with trisomy 13,18 , or other very severe but well recognised abnormalities undergo necropsy. Given the high prevalence of congenital heart disease in this group, it is likely that this also contributes to underestimation of the true prevalence of serious congenital heart disease.

Awareness of deaths from unrecognised congenital heart disease is important to paediatricians, paediatric cardiologists, and epidemiologists. Congenital heart disease is assuming increasing importance as a cause of perinatal and infant mortality as the prevalence of other severe malformations has been reduced by antenatal diagnosis and selective termination of pregnancy. ${ }^{8}$ If deaths from unrecognised heart disease are not taken into account, a falsely low picture of the prevalence of serious congenital heart disease will be obtained. Better awareness of the problem and education of both hospital paediatricians and the primary health care team may improve the recognition of congenital heart disease in the newborn and in early infancy and thus reduce infant mortality.

We are grateful to the steering groups of the NRFAS and NRS for access to their data, and to the Northern Regional Health Authority for financial support.

1 Rubin JD, Ferencz C, Brenner JI, Neill CA, Perry LW. Early detection of congenital cardiovascular malformaEarly detection of congenital cardiovascular malfor

2 Ferencz $C$. On the birth prevalence of congenital heart Ferencz C. On the birth prevalence of congen
disease. $f \mathrm{Am}$ Coll Cardiol 1990; 16: 1701-2.

3 Samanek M, Slavik Z, Zborilova B, Hrobonova V, Voriskova M, Skovranek J. Prevalence, treatment, and outcome of heart disease in live-born children: a prospective analysis of 91,823 live-born children. Pediatr Cardiol 1989; 10: 205-11.

4 Grabitz RG, Joffres MR, Collins-Nakai RL. Congenital heart disease: incidence in the first year of life. $A m \mathcal{J}$ Epidemiol 1988; 128: 381-8. 
5 Samanek M, Goetzova J, Benesova D. Causes of death in neonates born with a heart malformation. Int $\mathcal{f}$ Cardiol 1986; 11: 63-74.

6 Vesterby A, Nielsen K, Borg L, Paulsen S, Baandrup U. Congenital heart malformations in Jutland, Denmark: three year necropsy study in children aged $0-14$ years. $B r$ Heart f 1987; 58: 653-8.

7 Northern Regional Health Authority Coordinating Group. Perinatal mortality: a continuing collaborative regiona survey. BMF 1984; 288: 1717-20.

8 Northern Regional Survey Steering Group. Fetal abnormality: an audit of its recognition and management. Arch Dis Child 1992; 67: 770-4.

9 Ferencz C, Neill CA. Cardiovascular malformations: prevalence at livebirth. In: Freedom RM, Benson LN, Smallhorn JF, eds. Neonatal heart disease. London: Springer-Verlag, 1992: 19-29.

10 Martin GR, Perry LW, Ferencz C. Increased prevalence of ventricular septal defect: epidemic or improved diagnosis. ventricular septal defect: epid

11 Ferencz C, Rubin JD, McCarter RJ, Brenner JI, Neill CA Perry LW. Congenital heart disease: prevalence at livebirth. Am $\mathcal{F}$ Epidemiol 1985; 121: 31-6.
12 Allen HD, Taubert KA, Deckelbaum RJ, et al. Poverty and cardiac disease in children. Am $\mathcal{F}$ Dis Child 1991; 145: 550-3.

13 Fyler DC. Report of the New England regional infant cardiac program. Pediatrics 1980; 65 (suppl): $375-461$.

14 Hoffman JIE, Christianson R. Congenital heart disease in a cohort of 19,502 births with long-term follow-up. $A m \mathcal{F}$ Cardiol 1978; 42: 641-7.

15 Dickinson DF, Arnold R, Wilkinson JL. Congenital heart disease among 160480 liveborn children in Liverpool 1960 to 1969 . Br Heart f 1981; 46: 55-62.

16 Fixler DE, Pastor P, Chamberlin M, Sigman E, Eifler CW. Trends in congenital heart disease in Dallas County births 1971-1984. Circulation 1990; 81: 137-42.

17 Ferencz C, Neill CA, Boughman JA, Rubin JD, Brenner JI, Perry LW. Congenital cardiovascular malformations associated with chromosome abnormalities: an epidemiologic study. $f$ Pediatr 1989; 114: 79-86.

18 Tubman TRJ, Shields MD, Craig BG, Mulholland HC, Nevin NC. Congenital heart disease in Down's syndrome: two year prospective early screening study. BMf 1991; 302: $1425-7$. 